\title{
UMa Bienal EM TeMPOS de PANDEMia E A CENTRALIDADE DA CURADORIA EDUCATIVA
}

\author{
A Biennale in pandemic times and the centrality of educational curation
}

\author{
Igor Moraes Simões \\ UFRGS - Universidade Federal do Rio Grande do Sul, \\ Doutor em Artes Visuais \\ igor-simoes@uergs.es \\ https://orcid.org/0000-0001-7107-7951 \\ Luciana Gruppelli Loponte \\ UFRGS - Universidade Federal do Rio Grande do Sul, \\ Doutora em Educação \\ luciana.loponte@ufrgs.br \\ https://orcid.org/0000-0002-0552-0529
}

RESUMO: Este artigo tem como principal objetivo apresentar o programa educativo da 12. ${ }^{\text {a }}$ Bienal de Artes Visuais do Mercosul, realizado em 2020, em Porto Alegre, Rio Grande do Sul, Brasil, com o tema Feminino(S), Visualidades, ações e afetos, sob a curadoria geral de Andrea Giunta e curadoria educativa de Igor Moraes Simões . A mostra foi prejudicada pela pandemia do novo coronavírus que mudou, de forma irremediável, o planejamento da Bienal e de nossa vida. Além de uma breve contextualização da Bienal do Mercosul, conhecida internacionalmente como "bienal pedagógica", o texto evidencia o protagonismo da ação e da curadoria educativa durante a pandemia e a ausência de continuidade dessas ações por parte dos gestores da mostra.

Palavras-chave: Bienal do Mercosul, Brasil, Curadoria Educativa, Pandemia.

ABSTRACT: This article presents the educational program of the 12th Biennial of Mercosul Visual Arts, held in 2020, in Porto Alegre, Rio Grande do Sul, Brazil. The theme was Feminine(S), Visualities, Actions, and Affection, under the general curatorship of Andrea Giunta and educational curatorship of de Igor Moraes Simões. The new coronavirus pandemic occurred in the middle of the exhibition, which changed both the plans for the Biennial and all our lives. In addition to providing a brief contextualization of the Mercosul Bien- 
nial, internationally known as the "pedagogical biennial", this text highlights the prominence of action and educational curation during the pandemic and the lack of continuity on the part of the exhibition managers.

KeYwords: Mercosul Biennial. Brazil. Educational Curatorship. Pandemic.

RESUMEN: Este artículo tiene como principal objetivo presentar el programa educativo de la $12^{\mathrm{a}}$ Bienal de Artes Visuales del Mercosur, celebrada en 2020, en Porto Alegre, Rio Grande do Sul (Brasil), con el tema Femenino(S), visualidades, acciones y afectos, con el comisariado de Andrea Giunta y comisariado educativo de Igor Moraes Simões. La exposición quedó afectada por la pandemia del coronavirus, que cambió irremediablemente el curso de la planificación de la Bienal y de nuestras vidas. Además de una breve contextualización de la Bienal del Mercosur, conocida internacionalmente como «bienal pedagógica», el texto demuestra el protagonismo de la acción y del comisariado educativo durante la pandemia y la ausencia de continuidad de dichas acciones por parte de los gestores de la exposición.

Palabras clave: Bienal del Mercosur, Brasil, Comisariado educativo, pandemia.

RESUM: Aquest article té com a principal objectiu presentar el programa educatiu de la $12^{\mathrm{a}}$ Biennal d'Arts Visuals del Mercosur, celebrada en 2020, a Porto Alegre, Rio Gran do Sul (Brasil), amb el tema Femení(S), visualitats, accions $i$ afectes, amb el comissariat d'Andrea Giunta i comissariat educatiu d'Igor Moraes Simões. L'exposició va quedar afectada per la pandèmia del coronavirus, que va canviar irremeiablement el curs de la planificació de la Biennal i de les nostres vides. A més d'una breu contextualització de la Biennal del Mercosur, coneguda internacionalment com a «biennal pedagògica», el text demostra el protagonisme de l'acció i del comissariat educatiu durant la pandèmia i l'absència de continuïtat d'aquestes accions per part dels gestors de l’exposició.

Paraules clau: Biennal del Mercosur, Brasil, Comissariat educatiu, pandèmia. 


\section{Uma bienal de artes visuais pedagógica no sul do Brasil}

imagem do Brasil para muitas pessoas na Europa está associada a praias
tropicais ou futebol - é difícil escapar desses clichês. Além de rótulos, o Brasil apresenta muita diversidade de pessoas, culturas, climas, geografias e modos de viver. No sul do Brasil, distante dos holofotes da região sudeste e do eixo Rio-São Paulo, surgiu em 1997, na cidade de Porto Alegre, no estado do Rio Grande do Sul, a Bienal de Artes Visuais do Mercosul. Ambiciosa, a primeira bienal teve como principal propósito fazer um exame do desenvolvimento histórico da arte do continente a partir de 800 obras de 200 artistas dos países do Mercosul - Argentina, Bolívia, Brasil, Chile, Paraguai, Uruguai e Venezuela. Desde então, em 12 edições de formatos e alcances diversos, a Bienal do Mercosul tem feito história não apenas no Brasil, mas no mundo.

Para este artigo, ressalta-se o marco da 6 . $^{\mathrm{a}}$ edição da Bienal do Mercosul, em 2007. Esta edição intensificou sua internacionalização e teve mudanças profundas em seu programa pedagógico. Com curadoria geral de Gabriel Pérez-Barreiro, a mostra foi pensada a partir das proposições educativas de Luís Camnitzer, artista uruguaio que inaugurou a posição de curador pedagógico, que "atua como um embaixador do público e observa o evento com os olhos do visitante" (Camnitzer, 2009, p. 15). Esta edição teve sua ação pedagógica estendida, iniciada início meses antes da própria mostra e com um grande impacto no que se pensava sobre arte e educação na época, não apenas nessa edição específica da mostra, mas em várias outras exposições ao redor do mundo. Por muito tempo, o nome de "bienal pedagógica" tem sido associado a essa exposição. Ressalta-se também o nome da professora, pesquisadora e curadora Mônica Hoff, que fez parte da equipe da Bienal até a 9. ${ }^{\text {a }}$ edição, quando ocupou a posição de curadora de base e contribuiu, sobremaneira, para firmar o programa educativo, fazendo com que passasse a ser conhecido em todo o mundo.

Após esta breve contextualização da Bienal de Artes Visuais do Mercosul e de seu caráter marcadamente pedagógico, o principal objetivo deste artigo é apresentar o programa educativo da 12. ${ }^{a}$ Bienal de Artes Visuais do Mercosul, realizado em 2020, prejudicado pela pandemia do novo coronavírus e que mudou, de forma irremediável, o planejamento da Bienal e de nossa vida. 
Nesse processo, algumas decisões importantes tiveram que ser tomadas em relação à produção de material educativo em meio à pandemia e a concretização de uma mostra de arte contemporânea de forma totalmente remota e online. Em termos de organização deste artigo, apresentamos em primeiro lugar o modo como a curadoria educativa foi pensada em uma mostra de arte contemporânea que tinha como foco a centralidade, os feminismos, raça e descolonização e, em segundo lugar, o que foi possível fazer com o advento da pandemia de Covid-19 e a transformação do evento em uma exposição online. Por fim, tecemos algumas considerações finais, em que afirmamos a insistência de se estar juntos e a centralidade necessária dos programas educativos em exposições de arte contemporânea.

\section{I.I. Bienal I2: curadoria educativa, feminismos, raça, descolonização}

A Bienal 12 se apresentava sob o título Feminino(S), Visualidades, ações e afetos, sob a curadoria geral da argentina Andrea Giunta. A curadora propôs completar o time de adjuntos da Bienal com a brasileira Fabiana Lopes, curadora negra que trabalha com a arte brasileira, a polonesa Dorota Biczel, especialista em arte na América Latina e Igor Simões, pesquisador negro como curador educativo da mostra.

Havia no escopo da exposição um olhar alargado de questões que foram tratadas na Mostra Mulheres Radicais: arte latino-americana 1960-1985 com curadoria de Andrea Giunta e Cecilia Fajardo-Hill. Ali, a presença de mulheres negras e não cisgêneras era marcada como uma ausência. As pesquisas que se iniciaram para mostra de Porto Alegre partiam, assim, da necessidade de que estas experiências fossem centrais nas articulações de todo o time curatorial.

A escolha, na Bienal 12, pelo uso do termo curadoria educativa foi uma estratégia política assumida pelo curador Igor Simões. Aqui, para além dos debates que cercam os termos que nomeiam a ação educativa, estava em jogo negociar com a instituição a centralidade do programa no pensamento curatorial. Usar o termo curadoria educativa, nesta edição, foi a forma de reforçar

1. Exposição realizada na Pinacoteca do Estado de São Paulo em 2018. Ver mais em: https://pinacoteca.org.br/programacao/mulheres-radicais-arte-latino-americana-1960-1985/ 
que o educativo não vem depois, mas está lado a lado, o que ajuda a forjar as áreas de trânsito ilimitado de uma mostra. Não cabe aqui dissimular o fato de que há uma questão sistêmica. Tratou-se de jogar com a hierarquização da posição curatorial para, a partir de tal, reivindicar posições que o educativo sem o termo curadoria parece nem sempre conseguir atingir. Se a curadoria recorrentemente é entendida como o lugar de criação das mostras, usar o termo curadoria educativa é situar o educativo a partir desse lugar e, consequentemente, lidar de forma direta com as expectativas e enquadramentos sistêmicos.

Também há de se considerar que a Bienal 12 acontece a partir de uma Fundação a qual, ao longo dos anos, demonstrou que uma das forças principais das suas Bienais estava na centralidade do programa educativo. Havia no uso do termo curadoria educativa um esforço para falar à memória dessa instituição que ajuda a forjar essa expressão, a partir do trabalho de Luis Camnitzer na 6. ${ }^{\text {a }}$ edição da Bienal, em 2007. O trabalho da professora, pesquisadora e curadora Monica Hoff, até a 9. a edição foi, de maneira incontestável, uma contribuição para afirmar a importância do programa educativo. Vale ressaltar que o conceito de curadoria pedagógica foi criado no âmbito da 6. ${ }^{\text {a }}$ Bienal do Mercosul, realizada em 2007, em Porto Alegre, Rio Grande do Sul, Brasil. Segundo Camnitzer (2009), o conceito e a criação do cargo partiram de uma decisão de Gabriel Pérez-Barreiro, curador-geral da mostra, sendo que o próprio artista Luís Camnitzer foi o primeiro a ocupar a função: “O curador pedagógico é alguém que não influi na seleção dos artistas. É alguém que atua como um embaixador do público e observa o evento com os olhos do visitante" (Camnitzer, 2009, p. 15)². Esta tomada de posição da curadoria em relação às ações educativas modificou substancialmente a mostra, deixando uma marca profunda na Bienal do Mercosul, o que fez com que a iniciativa tivesse reconhecimento internacional. Esta era a instituição, que tem este registro, a relembrar o lugar do educativo no caráter de construtor das suas mostras.

2. Cabe destacar que o termo "curadoria educativa" já havia sido utilizado antes por Luís Guilherme Vergara em texto originalmente publicado em 1996 (Vergara, 2018). A posição de curador pedagógico foi retomada em algumas outras edições da Bienal do Mercosul e na Bienal de São Paulo, entre outras mostras. 
Outro fato relevante dessa etapa de nosso trabalho foi buscar pares constantes nas experiências educativas de instituições locais. Uma das primeiras ações ocorreu no Museu de Arte do Rio Grande do Sul Ado Malagoli MARGS, a partir de um encontro com os setores educativos dos museus e demais aparelhos culturais da cidade de Porto Alegre. Era preciso encontrar nossos pares. Não se tece um programa sozinho, principalmente quando se fala da experiência de uma Bienal que contribuiu, em grande parte, para as experiências de mediação e educação no cenário de origem da mostra, a capital gaúcha. Vale ressaltar novamente: criar um programa educativo significa, em larga medida, estar junto. Ainda nessa direção, era preciso que um dos principais públicos dos programas educativos estivesse representado. Como é possível pensar uma ação educativa que não esteja constantemente informada das vozes das professoras e professores? Outra estratégia adotada foi a chamada pública para docentes, estudantes de licenciaturas e mediadores que foram convidados para um debate público sobre as dimensões de um programa educativo e suas prioridades, quando pensados os protagonismos dos docentes de escolas e universidades, bem como dos educadores das instituições culturais. A partir de uma longa reunião, eles mesmos escolheram entre si os representantes que viriam a formar a Câmara de professores da Bienal 12. Um grupo de educadores acompanhou todas as ações que foram desenvolvidas pelo programa e participaram de reuniões nas atividades, garantido que sua voz fosse ouvida em todas as etapas do processo de trabalho. Mais uma vez, o sentido do programa esteve em estar junto com a maior quantidade possível de vozes em frentes amplas de diálogo e debate.

Talvez o elemento essencial para o programa educativo da Bienal 12 se explique pelo encontro entre a vontade de criar espaços onde o estar junto pudesse ser privilegiado e a necessidade de que esse estar junto estivesse baseado em decisões políticas que, necessariamente, enfrentariam as diferentes dimensões do feminino, profundamente, aliadas às noções de raça. Havia de se ouvir, mas as vozes privilegiadas deviam ser aquelas que, sendo nomeadas como silenciadas, produzem os mais importantes sons dos nossos tempos. Essa, foi desde sempre, a principal meta do programa educativo: estar junto, e juntos mirar no que importa para forjar um olhar sobreposto para analisar o mundo e suas assimetrias. 
Havia, antes de tudo, um aprendizado que ecoa nas vozes de feministas negras. $\mathrm{O}$ feminismo negro tem sido um lugar de confluência de inúmeras pautas que exigem a constituição de olhares solidários com o outro, suas assimetrias e desvãos e sua capacidade de inventar outras possibilidades de mundos nos quais queremos existir.

O primeiro lugar que ecoa essas vozes veio da literatura. Já vem de longe o aprendizado do que a literatura nos informa.

A imagem catalisadora das ações do programa educativo é devedora das palavras da escritora brasileira Ana Maria Gonçalves e do seu incontornável romance Um defeito de Cor (Gonçalves, 2008) no qual aprendemos a pensar os Brasis e suas gentes a partir das estratégias de vida de Kehinde. Antes de tudo havia Kehinde. Em cada ação, em cada novo agrupamento, havia Kehinde. Kehinde diante do espelho descobrindo a si. Kehinde inventando vida. Kehinde.

No programa educativo, que construía seus primeiros caminhos, foi o romance histórico Um Defeito de Cor (2008) que serviu de principal referência, que acompanhou a trajetória da protagonista do romance, uma mulher negra escravizada, desde a África, sua chegada ao Brasil e como negociou com a escravização, a liberdade e as interdições à sua existência e afirmação. Há uma sobrevivência nos modos de pensar a presença dessas sujeitas na sociedade brasileira que é perceptível no constante relegar dessas mulheres às figuras fixas das trabalhadoras domésticas em lares da classe média ou no corpo sexualizado e disponível. Os deslocamentos sociais e territoriais e as afirmações de uma presença histórica dessas mulheres em espaços de poder eram assim reafirmadas a partir dessa figura que flerta com a ficção e com os fragmentos da história.

O Romance torna-se assim lugar conceitual para as ações do programa educativo da Bienal que estabelece vínculos de uma memória que se acreditava, durante muito tempo, estar perdida e que reaparece como relâmpago necessário na lacuna de um registro sobre onde viemos e de qual lugar surgem nossas raízes. A escravização no Brasil não pode ficar relegada à experiência do passado. Antes disso, ela é elemento que atravessa nossas maneiras de 
pensar e de existir em uma sociedade assimétrica e, muitas vezes, desumanizadora. No entanto, a obra desenha, inscreve, rasga lugares para ver a existência negra no século XIX brasileiro. Há ali negros que leem e criam estratégias de aprendizado. Há o centro urbano tomado por homens e mulheres que se deslocam e negociam suas liberdades e aprisionamentos. Há a vida da Bahia, do Maranhão, do Rio de Janeiro, de São Paulo.

Há sobretudo uma mulher que acende a própria vida, ascende e atende sob o nome de Kehinde. A personagem empreende de Savalu até o Brasil, dos Brasis até as Áfricas e Europas. Inventa formas de vida, olhos de ver e ser vista, morre algumas vezes, vive muitas, aprende e ensina. Kehinde é a mulher negra com suas táticas de existir: a astúcia, a atenção, o olho atento ao afeto não distante da luta e dos saberes. É a capacidade de criar territórios a cada chegada. Em uma mostra, no Sul do mundo, como a Bienal 12, que toma como ponto de partida e de chegada os femininos e a arte em seus tensionamentos e possibilidades de invenção, tomar a figura de uma personagem que está entre a vida e a ficção - entre a memória e a escrita de passados necessários. E sobre a marca da mulher negra significa estabelecer que a mulher negra tem poder em diferentes sentidos de ser a imagem de um mundo já vivido e aquele desejado.

Sob o signo de Kehinde, o programa educativo foi desenhado por um conjunto de encontros que reuniram muitas mulheres e alguns homens em conversas que se pretenderam tramadas na horizontalidade com diferentes públicos e as convidadas. Era preciso que todes estivessem no mesmo espaço. Era preciso que se colocasse em xeque os próprios eixos e conceitos por onde se esboçava o programa educativo. Foram nove encontros debatendo raça e gênero como territórios da arte contemporânea, curadoria e femininos, a sala de aula como espaço de invenção e sabotagem, a proximidade entre as salas de exposições, as salas de aula e as salas de trabalho, femininos e culturas, os educativos e as instituições de arte, a presença das mulheres negras nas narrativas sobre arte, feminismos contemporâneos, imagens de controle, as proximidades e distanciamentos entre indígenas e negros a mediação e as urgências do contemporâneo. 
Em cada um dos encontros, um conjunto de mulheres colocava em movimento suas ideias e trajetórias, e ruíam e reconstruíam conceitos que viriam a forjar o que imaginávamos que seria um programa educativo para essa edição da Bienal.

Assim, a primeira ação do programa educativo foi abrir espaço onde ideias e pensamentos criassem lugares mínimos o que estaria por vir, a partir das falas das convidadas do Território Kehinde. Um sem-número de contranarrativas que reúne os elos criados pela imagem, o corpo e a voz da atriz, pesquisadora e professora negra Celina Alcântara que, na primeira noite do Território, entoava a canção, cantada em uníssono, que afirmava: “Quando eu venho de Luanda, eu não venho só".

Desde o princípio, a ideia é um conjunto de escolhas políticas do programa educativo: os rumos teriam como ponto de referência as vozes indispensáveis dessas mulheres e seus deslocamentos.

Um corpo negro não deve olhar o mundo a partir de uma mostra sem trazer consigo saberes, epistemologias que se confundem com suas estratégias de sobrevivência. Ele estava na posição de fazer escolhas e curar, a partir da arte, a história, a história da arte e a educação. Pela necessidade encontrar outras vozes, ele foi a fonte do programa público Território Kehinde.

O encontro entre a perspectiva Kehinde, que passou a ser conceito e seta, e a noção de dissenso do francês Jacques Ranciére, deu origem aos 12 Exercícios Coletivos de Dissenso. Foram 12 encontros nos quais as experiências sobre mediação precisavam transmitir os saberes e fazeres de mulheres de diferentes partes do país, convidadas para conduzir os exercícios. As perguntas que acompanhavam o processo de construção das propostas educativas da 12. ${ }^{a}$ Bienal do Mercosul versavam sobre o que acontece quando a mediação é entremeada por temas ligados às poéticas que discursam sobre formas não-binárias de femininos? Qual o impacto de mediar com ênfase os debates de mulheres na arena democrática? Pensamos "juntes", mais uma vez.

Tornou-se necessário o debate sobre temas prementes, como as mulheres, seus agrupamentos e vida democrática, as violências cotidianas, o debate 
legal e de direitos, as noções de arte entremeadas por debates feministas, as colonialidades e a descolonização na arte contemporânea, a acessibilidade de um espaço expositivo de artes visuais pensado para todes, incluindo os não videntes, as questões dos corpos negros e trans nas exposições como artistas e públicos.

Acima de tudo, era indispensável que essas discussões tivessem raízes profundas nas poéticas das mais de 70 artistas da Bienal 12. Os encontros reuniram feministas de diferentes vertentes teóricas, artistas, curadoras, educadoras, advogadas, antropólogas e historiadoras. Mais de 150 pessoas formaram grande fórum, compartilhando suas experiências pessoais que serviram de ponto de partida para lidar com as pautas da exposição e provocam uma agenda contemporânea comprometida com a apresentação de novas paisagens da vida no mundo e na arte.

O grupo não tinha hierarquia entre o mediador da exposição e o professor na sala de aula. Estas diferentes formas de pensar a arte contemporânea e suas confianças e desconfianças para com a educação criaram desenhos no espaço expositivo, que se tornaria uma grande arena de diferentes conceitos.

\section{I.2. Uma bienal em meio à pandemia}

A iminência de um país fechado pela Covid-19 representou o posicionamento tanto em relação ao papel do educativo como dos moldes da mostra no formato de bienal. A notícia de que a mostra física não se realizaria tomou de assalto a Fundação Bienal do Mercosul.

Durante algumas semanas todas as ações eram pensadas para uma futura abertura em data posterior. Nesse processo, o site ${ }^{3}$ passou a ser primeiramente um repositório das ações que já haviam sido desenvolvidas.

Uma das primeiras atitudes tomadas pelo grupo de curadores foi de buscar saber em que condições se encontravam as artistas ligadas à mostra. Cabe salientar que, algumas delas, que estavam em processo de construção de tra-

3. Site da Bienal do Mercosul: https://www.bienalmercosul.art.br/online 
balhos processuais, que eram uma das principais direções da mostra, estavam na cidade ou então em vias de chegar a Porto Alegre.

A partir de então, a curadoria empregou ferramentas para ajudar as artistas que já consideravam sua participação com pequenos vídeos com declarações de mulheres de diferentes partes do mundo falando sobre suas condições de saúde e sobrevivência com a pandemia.

Estes vídeos foram colocados no site, dando acesso aos possíveis públicos da mostra. Aos poucos, a dimensão do Afeto que residia no título da edição 12 , passou a ser protagonista.

O educativo, que estava em posição horizontal pela curadoria e por suas posições conceituais, passou a ser central.

Cabe aqui a pergunta: o que faz com que uma plataforma online ultrapasse sua dimensão de repositório ou um arquivo, sem prever os fluxos de pensamento decorrentes?

Essa decisão não partiu de forma orgânica por parte da Fundação Bienal do Mercosul. Uma das primeiras medidas foi a dispensa dos mediadores que haviam passado por etapas de estudo e preparação e estavam em vias de ser contratados. Em um primeiro momento, discutiu-se se aventou a redução do quadro já pequeno do setor educativo. No entanto, a existência do site deixou visível que o que o faria da mostra física uma mostra online não era apenas ser uma plataforma, mas se, a partir dela, produzir formas mínimas de vínculos e alianças.

Nesse instante, o programa educativo passou a ser central. Se, por um lado, ele já fazia parte da dimensão artística da mostra, por outro lado, essa centralidade se torna mais evidente ao se questionar o que molda uma exposição. A seleção, o estudo e a disposição dos trabalhos em um determinado espaço são fatores primordiais, mas oque está em jogo também é o universo conceitual, que se cria a partir dessas aproximações e distanciamento de propostas poéticas díspares, mas que convivem em um determinado período. 
Por conseguinte, o intangível passou a ser o principal material de trabalho do programa educativo. A noção de que deveríamos insistir em formas de estar juntos passou a ser a seta de um conjunto de ações que tinha essa premissa.

"A insistência de estar juntos" acionou um conjunto de práticas que se iniciaram com a transformação de uma série de proposições voltadas para lidar coma proximidade em tempos de afirmação do isolamento.

A primeira ação foi adaptar um material que tinha sido pensado para provocar e incentivar deslocamentos imprevistos para os públicos no espaço expositivo. As 12 proposições para a Bienal 12 eram um conjunto de ações que provocavam trajetos que se davam por buscas do público a partir de alguns eixos possíveis, que foram centrais na ideia da mostra e que não necessariamente estavam dados pelo espaço. Convites para pensar práticas de mulheres cis e não cis, negras, indígenas, a insurgência da arte trans, o papel da colonização nas assimetrias da vida latino-americana estavam postos nessas atividades que agora eram provocadoras do público para deslocamentos no site. Elas estavam propondo que o público fizesse suas diferentes trajetórias num espaço que seria intangível.

A proposta foi complementada por lives, ou transmissões de vídeo ao vivo, que passaram a ser populares em função da necessidade de atividades remotas. A Bienal 12 não foi a única a adotá-las, elas estiveram presentes na programação de outras instituições.

Ainda alicerçados na noção de estar juntos, foram propostos encontros em cada uma das lives entre diferentes figuras, desde artistas, educadores, curadores reunidos para pensar não apenas o impensável futuro diante da crise, mas, antes de tudo, pautas que anteciparam esse estado de coisas e, acima de tudo, as formas de resistência e enfrentamento que partiam das perspectivas de um multiverso de sujeitos que foram, na constituição dos cânones ocidentais, relegados a nota de rodapés. Eram essas vozes que interessavam ao programa e, com isso, pautas como a presença das mulheres negras na arte brasileira, a emergência de curadorias de pesquisadores racializados, as perspectivas poéticas de artistas que interseccionam as questões indígenas e de gênero e o papel da educação na invenção de horizontes possíveis e com- 
partilhados, foram os motivadores dos convites e das ações que ocorreram ao longo de 12 encontros.

Havia ainda uma questão que movia nossas dúvidas: o que significava pensar um material educativo em tempos pandêmicos? As escolas haviam migrado para atividades mediadas por telas, expondo as lacunas das já defasadas condições de trabalhos de professores por todo o continente, além da falsa crença de um acesso irrestrito aos meios digitais por parte da população de crianças e jovens em situação de aprendizado.

A dúvida e a insistência de estar juntos abriram o caminho para o programa intitulado: Laboratório coletivo Bienal 12 - Material educativo em tempos pandêmicos, que partiu de uma chamada aberta a professoras e educadores de instituições que quisessem, junto com artistas convidados, pensar o que pode ser um material de uso pedagógico num contexto de completa exceção.

Houve encontros que reuniram artistas da mostra e educadores para pensar dimensões, como a força dos coletivos e das associações de mulheres, tais como as práticas desenvolvidas pelo coletivo argentino Nosotras proponemos, que reúne a militância política e cidadã e os espaços da arte latino-americana. Com a artista trans Elle de Bernardini, professoras puderam pensar quais são as complexidades que envolvem a prática educativa baseada nesses temas em um momento de diminuição radical às liberdades em contextos de avanço de pautas conservadoras na sociedade brasileira. Com a artista negra brasileira Renata Felinto, o papel das mulheres negras na reconfiguração da arte latino-americana e afrodiaspórica foi o tema norteador. Feminicídios em países como a Argentina deram a direção do encontro com a artista portenha Fatima Pecci Carou. Em cada encontro, pelo menos duas propostas de abordagem eram desenvolvidas coletivamente e passariam a orientar o material educativo da mostra.

Ao fim do processo, a equipe do educativo deu corpo e forma às principais questões tratadas de forma coletiva e surgiu o material que recebeu o nome de "A insistência de estar juntos - material educativo Bienal 12" que se compõe de um conjunto de práticas e proposições educativas que privilegiam 
o coletivo possível em tempos pandêmicos ao mesmo tempo que projetam movimentos que possam ser desenvolvidos em contextos após a pandemia.

\section{Sobre a insistência de estar juntos: algumas considerações}

Estabelecer um programa educativo, parece ser antes de tudo buscar construir formas politicamente situadas de escrita coletiva para a vida comum. Para além de uma presunção de um conjunto de proposições baseadas em saberes cristalizados, o que entra em jogo é a possibilidade de mover dúvidas, perguntas e estranhamentos em uma constelação de sentidos para a experiência de estar juntos. Essa foi a principal direção do programa educativo da Bienal 12.

Antes da proposição da plataforma curatorial , havia um histórico de ações que reservam um lugar caro para as noções relacionadas à educação na perspectiva da Bienal do Mercosul. Não há nenhuma dúvida na afirmação de que experiências como aquelas desencadeadas pelo professor e artista Luis Camnitzer foram o lastro para retomar inclusive a noção de curadoria educativa ou pedagógica. No entanto, o primeiro contato com a Fundação Bienal nos colocou diante de algumas dificuldades impostas pela frágil manutenção, por parte da Fundação, no que concerne à memória do seu próprio histórico com a dimensão pedagógica da mostra.

Entre outros elementos, é possível citar a ausência de continuidade de equipes do setor, na transição entre as edições da mostra. A experiência anterior, com as presenças consecutivas de nomes como o da curadora e pesquisadora Mônica Hoff até a nona edição da mostra, atestam que a perspectiva histórica serviria para manter um fio condutor na relação de uma Bienal ao sul do Brasil e ao sul do hemisfério sul, que se destacou no cenário internacional, especialmente a partir de seu comprometimento com a educação.

Nesse sentido, as perspectivas baseadas na poética e política de grupos apresentados como minorizados, o destaque a respeito do caráter de criação e constituição da Bienal a partir da proposta do educativo e demais proposições, não se assentam como garantia para ações futuras. De certa forma, 
o que se percebe é uma dinâmica comumente encontrada nas instituições de arte que abrigam pautas que rompem paradigmas, mas que se projetam mais sobre o episódio lacunar da exposição do que sobre uma postura política de enfrentamento e questionamento das próprias bases hegemônicas que constituem a instituição.

Ainda assim, a experiência de privilegiar o coletivo conectado a um olhar atento sobre o que mulheres, negros, indígenas, trans e outros grupos propõem em termos das noções do que seja contemporâneo, e da arte que recebe esse complemento, ficam como uma seta para pensarmos o quanto o próprio campo da arte, caso esse termo ainda seja válido, está ou não disposto a se reconfigurar de acordo com o que vem sendo exigido pelos diferentes extratos da sociedade.

A Bienal 12 tomou a insistência de estar junto como plataforma acionadora dos saberes múltiplos a partir da pluralidade de vozes. Do coro, ao invés do solo. De fato, a imersão da vida diária em um contexto de completa exceção advindo da pandemia acentuou a centralidade que os educativos têm na implementação de ações e pensamentos para tempos dos mais tenebrosos até aqueles que buscamos inscrever como horizonte possível. Uma mostra vai além do que está exposto em seus displays. Ela se configura e se completa a partir dos olhares e das dúvidas.

Para além de uma conclusão, o que fica desse processo é a certeza de que o programa educativo pode ser o lugar que afirma de forma positiva a desconfiança. De que forma? Desconfiando de tudo que está posto. Do universo de verdades absolutas sobre as artes e as gentes, das configurações em bloco das proposições institucionais. De fato, nessa acepção é possível afirmarmos que o educativo, quando mostrado como seu devido protagonismo pode ser, por excelência, o espaço privilegiado de uma nova dimensão da crítica institucional. No entanto, para isso é necessário que a instituição reconheça e se coloque em estado de disponibilidade para o insondável que surge no tempo da troca, da coletividade e da dúvida. 


\section{Referências}

Camnitzer, Luís. 2009. Introdução. In: Pérez-Barreiro, Gabriel, Camnitzer, Luís (org.). Educação para a arte, Arte para a educação. Porto Alegre: Fundação Bienal do Mercosul.

Gonçalves, Ana Maria. 2008. Um defeito de cor. Rio de Janeiro: Record.

Helguera, Pablo, Hoff, Mônica (orgs.). 2011. Pedagogia no campo expandido. Porto Alegre: Fundação Bienal do Mercosul.

Vergara, Luiz Guilherme. 2018. Curadora educativa: percepção imaginativa/ consciência do olhar. In: Cervetto, Renata; López, Miguel A. (orgs.). Agite antes de usar. Deslocamentos educativos, sociais e artísticos na América Latina. São Paulo: SESC São Paulo, 2018. 